\title{
Correspondence
}

\section{International Volunteers' Programme}

Sin. I would like to share my experience of the - College's new International Volunteers' Programme. I spent 3 months last year working for

Correspondence

is welcome on

any of the articles

or issues raised

in International

Psychiatry. Letters

of no more than

500 words should

be sent to

the Editor,

Hamid Ghodse, email hghodse@ sgul.ac.uk the World Health Organization in Aceh, Indonesia, following the Boxing Day tsunami of 2004, where we were working towards setting up a community-based mental health service with the Ministry of Health, Indonesia. As a specialist registrar working in London, I brought my experience of community mental healthcare as practised in the UK into a multinational and multidisciplinary team to work with our Indonesian colleagues in developing a system that would meet the aspirations as well as the social, cultural and economic realities of modern Indonesia.

I found it a wonderful and enriching experience, particularly as I am lucky enough to speak Indonesian reasonably fluently. I was involved in the development of a curriculum and training, as well as having input into systems development. A lot of time was spent with fellow healthcare professionals, learning about local issues and challenges, and looking at ways of addressing them. Probably the most useful thing was sharing some of my day-to-day clinical experience in managing patients in the community with fellow clinicians who have had experience only of a more custodial approach to psychiatry. I had the opportunity to lead a team of my Acehnese colleagues to see a community mental health team in action in neighbouring Malaysia.

For me, the programme was extremely helpful in arranging this experience. In particular, I had to arrange unpaid leave from my National Health Service job, and I believe that this would have been diffcult without the support of the College. I also had additional support and mentoring via email from Professor Jenkins in the UK, as well as extremely helpful advice and support from the College's Western Pacific International Division, principally from Professor Deva in Malaysia.

I would thoroughly recommend the Programme to any specialist registrar. I would also recommend it to colleagues in the developing world who are looking at ways of adapting experiences and practices from the UK to local services. Specialist registrars usually have at least 5 years' specialist training and have all passed their MRCPsych examinations. Many are actively involved in research and service development, and yet, because of their unique position of being supernumerary to service requirements in the National Health Service, are more able to spend a longer period abroad.

The International Volunteers' Programme is not only an ideal opportunity for capacity building in developing countries but also a wonderful opportunity for two-way learning and developing practices to bring back to the UK.

lan Soosay

Specialist Registrar and Honorary Lecturer, University College London, email r.soosay@ucl.ac.uk

\section{Health inequalities}

Cine Your editorial in the April 2006 issue SIP: of International Psychiatry highlighted the important and complex relationships between mental illness and poor physical health. It is difficult to address these health needs in a climate of constrained resources and increasing specialisation. Health promotion for patients with severe mental illness is particularly challenging. Much attention is given to the management of physical health problems in patients with mental illness; this is generally related to the reversal of the unwanted effects of psychotropic medications and lifestyle modification, and may be highly proactive, involving frequent invitations and follow-up (Osborn et al, 2003). Behavioural lifestyle interventions, for example for managing body weight, albeit intuitively appealing, may fail if the pharmacological properties of medications are not sufficiently taken into account (Werneke et al, 2003).

Implementation of population-based cancer (e.g. breast and cervical) screening may be even more difficult to achieve. Although most of the studies have been conducted in patients with learning disabilities, evidence is emerging that women with severe mental illness may also be less likely to take up such screening (Bergmann et al, 1996; Lasser et al, 2003; Werneke et al, in press). Psychiatrists and keyworkers may not be sufficiently familiar with the process of these screening programmes to offer an effective but balanced intervention. Patients with mental illness may more 
often postpone presentation or otherwise delay the diagnostic process (Kunkel et al, 1997). Yet, for some screening programmes, including mammography for breast cancer, highly proactive encouragement may not be appropriate, because the benefit of detecting cancers early and at a more treatable stage needs to be weighed against the risk of false-positive results.

Although in many patients the anxiety related to false-positive cancer screens seems transient (McGovern et al, 2004), others may experience severe and persistent distress, despite reassurance (Barton et al, 2004). In contrast to the case in many women with significant learning disabilities, most women with severe mental illness have the capacity to consent unless acutely unwell. However, even if capacity to consent is retained, residual symptoms, including bluntness of affect and pervasive anxiety, as two possible extremes of emotional disturbance, may lead to different decisions over whether to attend screening. Most probably, for patients with severe mental illness, cancer screening can be facilitated only if the interface between primary and secondary care works well. Keyworkers could facilitate screening by ensuring that their patients understand the benefits and risks of screening, and that invitation letters are not missed, or by arranging postponement of screening invitations for patients who are acutely unwell until their capacity to consent is restored. Once patients have attended screening it is important to ensure that abnormal results are followed up. To promote cancer prevention appropriately and effectively, psychiatrists and mental health teams would benefit from some specific training in this area.

Ursula Werneke

Consultant Psychiatrist and Honorary Senior Lecturer, Homerton University Hospital, Department of Psychiatry, London E96SR, UK, email ursula.werneke@elcmht.nhs.uk

Barton, M. B., Morley, D. S., Moore, S., et al (2004) Decreasing women's anxieties after abnormal mammograms: a controlled trial. Journal of the National Cancer Institute, 96, 529-538.

Bergmann, J. B., Sigurdson, J. A. \& Sigurdson, K. (1996) What attendance can be achieved for Pap smear screening? Scandinavian Journal of Primary Health Care, 12, I52-158.

Kunkel, E. J., Woods, C. M., Rodgers, C., et al (1997) Consultations for 'maladaptive denial of illness' in patients with cancer: psychiatric disorders that result in noncompliance. Psychooncology, 6, 139-149.

Lasser, K. E., Zeytinoglu, H., Miller, E., et al (2003) Do women who screen positive for mental disorders in primary care have lower mammography rates? General Hospital Psychiatry, 25, 214-216.

McGovern, P. M., Gross, C. R., Krueger, R. A., et al (2004) Falsepositive cancer screens and health-related quality of life. Cancer Nursing, 27, 347-352.

Osborn, D. P., King, M. B. \& Nazareth, I. (2003) Participation in screening for cardiovascular risk by people with schizophrenia or similar mental illnesses: cross sectional study in general practice. BMJ, 326, I| 22-||23.

Werneke, U., Taylor, D., Sanders, T. A. B., et al (2003) Management of antipsychotic-induced weight gain: a review. Acta Psychiatrica Scandinavica, 108, 252-259.

Werneke, U., Horn, O., Maryon-Davis, A., et al (in press) Uptake of screening for breast cancer in patients with mental health problems. Journal of Epidemiology and Community Health.

\section{International recruitment: individual choice or ethical dilemma?}

C. I am writing in response to the point of view put forward by Dr Amit Malik concerning international recruitment in the January 2006 issue of International Psychiatry (pp. 22-23). The article highlights a number of issues; however, I would like to point out the differences between those recruited as consultants and those who come as trainees.

In relation to consultants, national governments need to put in place a structure which respects and values health professionals. They do not need extravagant salaries and generous incentives, but rather adequate remuneration, job satisfaction, support networks and good opportunities for their families. All these have been looked into by the Department of Health in the UK. Can you blame any health professional for wanting to move for such reasons? I believe we must look into these issues, for happy health professionals are able to give a better service to the people they serve.

With regard to trainees, I believe a number come to the UK for the issues highlighted by Dr Malik. However, having attained the higher qualifications they do not return to their home countries for many of the reasons highlighted above. The UK has always welcomed people who have more to offer to its citizens and in return has provided them with adequate remuneration and support. However, we need to analyse what implications the recent change in visa regulations (brought in without any consultation) will have for those trainees here and those who are planning to come.

Some of the issues which may have persuaded the Department of Health could be the unemployed local graduates and restructuring of the National Health Service (NHS). We already have the largest number of medical students in training and more countries are set to join the European Union (EU). We have had a major influx from Poland already. Romania and Bulgaria are set to join the EU on I January 2007. We have major restructuring of the $\mathrm{NHS}$ and expect a reduction in the number of consultants. This can already be seen in Scotland, where there is a freeze in the number of consultant posts.

With the current reforms in place, I do not believe the ethical dilemma will exist for much longer. The time to discuss this further, with respect to the UK, has passed. With respect, I think there is more to discuss in world forums - for example, war, poverty, hunger, water supply and fairer world trade.

Mukesh Kripalan MBBS MD MRCPsych Executive Member, Northern and Yorkshire Divisions, Collegiate Trainees Committee of the Royal College of Psychiatrists, UK, emailmkripalani@gmail.com
For the changes in visa regulations see http://www.ind. homeoffice.gov. uk/ind/en/home/ laws__policy/ immigration_rules/ explanatory memorandum 10.

html 